\title{
Mortality study of employees with potential exposure to epichlorohydrin: a 10 year update
}

\author{
Shan P Tsai, Elizabeth L Gilstrap, Charles E Ross
}

\begin{abstract}
Objectives-A 10 year extension of follow up (up to 1993) of 863 employees who had potential exposure to epichlorohydrin at two chemical plants between May 1948 and December 1965 was conducted to further evaluate the previously reported potential association between exposure to epichlorohydrin and heart disease.

Methods-The mortality observed was compared with that expected from the death rates from the local male population where these chemical plants are located. Workers were assigned to one of five exposure categories based on their job with the highest level of potential exposure. Vital status was ascertained to the end of 1993.

Results-Among diseases of particular interest, there were no excess deaths from heart disease (standardised mortality ratio (SMR) 63.3), lung cancer (SMR 63.8), or non-malignant respiratory disease (SMR 37.7) for employees with 20 or more years after first exposure. Based on the level of potential exposure to epichlorohydrin, mortality for heart disease was slightly higher (SMR 75.7, 95\% confidence interval $(95 \% \mathrm{CI}) 51 \cdot 8-106 \cdot 7)$ in the moderate to heavy exposure group than in the none to light exposure group (SMR 59.5, 95\% CI 37.7-89.3); this difference is well within the range of random variation. The SMR for heart disease was 90.4 among employees who had both probable exposure to allyl chloride and moderate to heavy exposure to epichlorohydrin, although it was 88.1 among employees who had moderate to heavy potential exposure to epichlorohydrin but no exposure to allyl chloride.
\end{abstract}

Conclusions-This study does not support an association between exposure to epichlorohydrin and heart disease or lung cancer. There were no additional deaths from leukaemia in this update; the raised SMR for leukaemia noted in the previous study has substantially decreased from $500 \cdot 0$ to $161 \cdot 3(95 \%$ CI $33 \cdot 2-471 \cdot 0)$ and is not significant. The overall mortality and cancer mortality of employees potentially exposed to epichlorohydrin continued to be lower than that of the local population.

(Occup Environ Med 1996;53:299-304)

Keywords: mortality study; epichlorohydrin; heart disease
In 1990, Enterline et al reported the mortality experience of employees who had potential exposure to epichlorohydrin in 1948-65 from two Shell Oil Company plants ${ }^{1}$ (one in Texas, one in Louisiana). In that study, the cohort members had been followed up and deaths identified up to 1983 . The main finding was an apparent dose-response relation between exposure to epichlorohydrin and heart disease. This was primarily due to the unusually low mortality for heart disease in the lower exposure group (standardised mortality ratio (SMR) $39 \cdot 2$, based on five deaths); the mortality for the higher exposure group (SMR 105.4 , based on 17 deaths) was about the same as the general population in the local communities. Enterline et al also suggested that employees with potential exposure to both epichlorohydrin and allyl chloride were possibly at increased risk of heart disease. ${ }^{1}$ The SMR for cardiovascular disease was 120.7 (16 deaths) for 160 employees where allyl chloride and moderate to heavy exposure to epichlorohydrin may have occurred. The SMR was $65 \cdot 1$ (five deaths) for 88 employees who had moderate to heavy exposure to epichlorohydrin but none to allyl chloride.

Several epidemiological studies in Europe ${ }^{2}$ and in the United States ${ }^{3-8}$ have examined the health effects of exposure to epichlorohydrin through normal industrial operations and production. Because there remains considerable interest in the possible human health effects of epichlorohydrin, we have extended the vital status follow up of the epichlorohydrin cohort, originally assembled by Enterline and his colleagues ${ }^{1}$, up to 1993 . The additional 10 years of follow up add substantial person-years to the original study and enhances the ability to find whether there is increased mortality from heart disease, particularly among those who had potential exposure to allyl chloride and moderate to heavy exposures to epichlorohydrin.

\section{Methods and materials}

The production of epichlorohydrin started in May 1948 at the Texas plant and in April 1955 at the Louisiana plant. At the Texas plant, the cohort was developed from quarterly departmental seniority lists. Shift foremen were also identified and included in the cohort. Maintenance employees were not included as they could not be identified with any single department. A total of 474 men who had at least three months of employment where exposure to epichlorohydrin could have 
occurred from 1948 to 1965 were identified. At the Louisiana plant, the cohort includes both hourly and salaried employees $(n=389)$ with six months or more potential exposure by the end of 1965. Maintenance employees who were employed for six months or more from April 1955 to July 1957 were included as this plant produced only epichlorohydrin during that period. Both plants remain in operation today; thus, the cohort includes those employees with continued potential exposure after 1965. These eligibility criteria were developed by Enterline et al for the original study which covered the same 863 employees.

For the previous study, a panel of industrial hygiene personnel and current and former employees assigned every employee into one of the five potential exposure categories, heavy, moderate, light, none, or unknown. This assignment was based on each worker's job with the highest potential level of exposure. The details of the study design, cohort identification, and exposure classification were described at length in an earlier article published in this fournal. ${ }^{1}$ A complete and detailed work history was not collected for the original study.

The two cohorts were followed up for deaths up to 1993 with the company records and external sources. After comparison with the company records, the cohort file was matched with both the national death index and the Social Security Administration's death master file for identification of vital status. Those employees who had left work and who were not identified by the national death index search or the Social Security Administration search were assumed to be alive. Death certificates were obtained for all of the decedents but one. For each death, the underlying cause of death was coded independently by two trained nosologists according to rules of the international classification of diseases (ICD) in effect at the time of death.

An employee entered the follow up on the day he met the eligibility criteria-that is, three months (Texas plant) or six months (Louisiana plant) of potential exposure to epichlorohydrin. Person-years were accumulated from the entry date to the date of death or the end date of the study, whichever came first. The comparative mortality analysis of this update study was based on the period of follow up after 1960 as in the original study; thus, person-years before 1960 were not included in the calculation of expected deaths.

Mortality excesses and deficits in this study are expressed as $\mathrm{SMRs}^{9}$ which were calculated with the occupational cohort mortality analysis program $^{10}$ (OCMAP) as a ratio of the observed to expected number of deaths multiplied by 100 . The expected number of deaths were adjusted for age, race, and calendar time based on the cause-specific death rates for the period 1960-89, and were computed by multiplying the age, race, and calendar time specific person-years of the study cohort by the rates of the corresponding comparison population. For the Texas plant, rates for Harris County (the county in which the Texas plant is located) were used, and for the Louisiana plant, rates for a three parish area including $\mathrm{St}$ Charles, St John, and Jefferson parishes were used. Most employees in Louisiana live in one of the three parishes, and the plant is located in St Charles parish. For the period 1990-3, expected numbers of deaths were calculated based on 1985-9 rates from the respective local communities. The county or parish mortalities that were used to calcuate the expected numbers of deaths were obtained from the mortality and population data system provided by the Department of Biostatistics, Graduate School of Public Health, University of Pittsburgh. ${ }^{11}$ The 95\% confidence interval (CI) for each SMR was calculated and its deviation from 100 was tested assuming a Poisson distribution for the observed deaths with a two sided test of significance. ${ }^{12}$

\section{Results}

A total of 863 people were included in the current analysis. There were three deaths before 1960 and one worker was lost to follow up before 1960. For the 1960-93 follow up period, $684(80 \%)$ cohort members were known to be alive, and 175 (20\%) were dead. Only $1 \%(n=7)$ of the cohort were actively employed at the end of follow up. The average age at entry into the follow up was 29 years. The total number of person-years of observation was 27008 , and the mean duration of follow up was 35 years. Because the study subjects were those who had potential exposure to epichlorohydrin during the period 1948-65, the minimum time since first exposure for more than $95 \%$ of study subjects was 28 years or longer.

Table 1 shows the observed and expected number of deaths, SMRs, and their $95 \%$ CIs for selected causes of death for the total cohort and for employees with 20 or more years since first potential exposure to epichlorohydrin. The overall mortality during the period 1960-93 was significantly lower than the comparison local populations with an SMR of $60 \cdot 7$ (95\% CI 52.2-70.6). The SMR for all cancer was $23 \%$ lower than the comparison populations (SMR 77.3, 95\% CI 59.5-100.3). Among diseases of particular interest, there were no excess deaths from lung cancer (SMR $70 \cdot 7,95 \%$ CI $44 \cdot 8-106 \cdot 0)$, heart disease (SMR $64 \cdot 5,95 \%$ CI $50 \cdot 7-81 \cdot 8$ ), or nonmalignant respiratory disease (SMR 32.6, $95 \%$ CI $10 \cdot 6-76 \cdot 0)$. No significant increases of mortality were found for any cause of death.

The SMRs for cancer of several sites showed non-significant increases, although these were based on small numbers of deaths. These included cancer of the prostate (SMR $216 \cdot 8,95 \%$ CI $93 \cdot 4-427 \cdot 1)$ and malignant melanoma of the skin (SMR 238.1, 95\% CI $49 \cdot 0-695 \cdot 2)$. There were no additional deaths from leukaemia in this update with three observed deaths and 2.4 expected (SMR $123 \cdot 5,95 \%$ CI $25 \cdot 4-360 \cdot 5$ ).

Mortality results for employees with 20 or more years since first potential exposure are also presented as long latency periods are usu- 
Table 1 Observed and expected deaths and SMRs for selected causes of death among employees with potential exposure to epichlorohydrin, 1960-93

\begin{tabular}{|c|c|c|c|c|c|c|}
\hline \multirow[b]{2}{*}{ Cause of death (ICD-8) } & \multicolumn{3}{|c|}{ Total population } & \multicolumn{3}{|c|}{$\geqslant 20$ y Since first potential exposure } \\
\hline & Observed & Expected & $S M R(95 \% C I)$ & Observed & Expected & SMR $(95 \% C I)$ \\
\hline \multirow{3}{*}{$\begin{array}{l}\text { All causes of death }(000-999) \text { : } \\
\text { All malignant neoplasms (140-209): } \\
\text { Digestive system and peritoneum: }\end{array}$} & 175 & $288 \cdot 11$ & $60 \cdot 7(52 \cdot 2-70 \cdot 6)$ & 143 & $226 \cdot 70$ & $63 \cdot 1(53 \cdot 4-74 \cdot 5)$ \\
\hline & 60 & $77 \cdot 57$ & $77 \cdot 3(59 \cdot 5-100 \cdot 3)$ & 55 & $66 \cdot 23$ & $83.0(63 \cdot 2-108 \cdot 9)$ \\
\hline & 8 & $16 \cdot 85$ & $47 \cdot 5(20 \cdot 5-93 \cdot 5)$ & 8 & $14 \cdot 43$ & $55 \cdot 4(23 \cdot 9-109 \cdot 2)$ \\
\hline Stomach (151) & 1 & 1.96 & $51.0(1$. & 1 & 1.56 & $64 \cdot 1(1 \cdot 6-357 \cdot 1)$ \\
\hline Large intestine (153) & 3 & $6 \cdot 33$ & $47 \cdot 4(9 \cdot 8-138 \cdot 4)$ & 3 & $5 \cdot 52$ & $54 \cdot 3(11 \cdot 2-158 \cdot 7)$ \\
\hline Rectum (154) & 0 & $1 \cdot 26$ & - & 0 & 1.05 & - \\
\hline Biliary passages and liver & & & & & & \\
\hline$(155-156)$ & 1 & $1 \cdot 67$ & $59.9(1.5-333 \cdot 5)$ & 1 & $1 \cdot 50$ & $66 \cdot 7(1 \cdot 7-371 \cdot 3)$ \\
\hline Pancreas (157) & 3 & $3 \cdot 54$ & $84 \cdot 7(17 \cdot 5-247 \cdot 5)$ & 3 & $3 \cdot 01$ & $99 \cdot 7(20 \cdot 5-291 \cdot 0)$ \\
\hline Lung (162) & 23 & $32 \cdot 55$ & $70 \cdot 7(44 \cdot 8-106 \cdot 0)$ & 18 & $28 \cdot 21$ & $63.8(37.8-100 \cdot 8)$ \\
\hline Prostate (185) & 8 & 3.69 & $216 \cdot 8(93 \cdot 4-427 \cdot 1)$ & 8 & 3.50 & $228 \cdot 6(98 \cdot 5-450 \cdot 3)$ \\
\hline Kidney (189) & 2 & $2 \cdot 20$ & $90 \cdot 9(11 \cdot 0-328 \cdot 2)$ & 2 & 1.91 & $104 \cdot 7(12 \cdot 7-378 \cdot 0)$ \\
\hline Malignant melanoma of skin (172) & 3 & $1 \cdot 26$ & $238 \cdot 1(49 \cdot 0-695 \cdot 2)$ & 3 & 0.93 & $322 \cdot 6(66 \cdot 5-941 \cdot 9)$ \\
\hline Central nervous system (191-192) & 2 & $2 \cdot 37$ & $84 \cdot 4(10 \cdot 2-304 \cdot 6)$ & 2 & $1 \cdot 83$ & $109 \cdot 3(13 \cdot 2-394 \cdot 5)$ \\
\hline All lymphopoietic tissue $(200-209)$ & $\overline{7}$ & $6 \cdot 48$ & $108 \cdot 0(43 \cdot 3-222 \cdot 5)$ & 7 & $5 \cdot 11$ & $137 \cdot 0(54 \cdot 9-282 \cdot 2)$ \\
\hline $\begin{array}{l}\text { Leukaemia and aleukaemia } \\
\text { (204-207) }\end{array}$ & & & & & & \\
\hline$(204-207)$ & 3 & $2 \cdot 43$ & $123 \cdot 5(2$ & 3 & $1 \cdot 86$ & $161 \cdot 3$ \\
\hline All other malignant $\mathrm{n}$ & 7 & $12 \cdot 17$ & $57 \cdot 5(23 \cdot 1-118 \cdot 5$ & 7 & $10 \cdot 31$ & $67 \cdot 9(27 \cdot 2-139 \cdot 9)$ \\
\hline Cerebrovascular disease $(430-438)$ & 8 & 11.99 & $66 \cdot 7(28 \cdot 8-131 \cdot 4)$ & 4 & $9 \cdot 69$ & $41 \cdot 3(11 \cdot 2-105 \cdot 7)$ \\
\hline $\begin{array}{l}\text { All heart disease }(390-398,400,401 \text {, } \\
404,410-414)\end{array}$ & 71 & $110 \cdot 10$ & $64 \cdot 5(50 \cdot 7-81 \cdot 8)$ & 56 & $88 \cdot 44$ & $63 \cdot 3(48 \cdot 3-82 \cdot 9)$ \\
\hline Non-malignant respiratory disease & & & & & & \\
\hline$(460-519)$ & 5 & $15 \cdot 33$ & $32 \cdot 6(10 \cdot 6-76 \cdot 0)$ & 5 & $13 \cdot 27$ & $37 \cdot 7(12 \cdot 2-87 \cdot 8)$ \\
\hline Cirrhosis of liver (571) & 2 & 8.93 & $22.4(2 \cdot 7-80 \cdot 9)$ & 2 & $6 \cdot 46$ & $31 \cdot 0(3 \cdot 7-111 \cdot 8)$ \\
\hline All accidents (E800-E949) & 10 & $17 \cdot 33$ & $57 \cdot 7(27 \cdot 7-106 \cdot 2)$ & 5 & $7 \cdot 92$ & $63 \cdot 1(20 \cdot 5-147 \cdot 1)$ \\
\hline
\end{tabular}

ally required for the development of chronic diseases (table 1). The mortality pattern of this group is similar to that for the total cohort although the SMRs were generally higher. The SMRs for all causes of death and for all cancers were 63 and 83, respectively. The mortality for heart disease was significantly lower (SMR 63.3, 95\% CI 48.3-82.9). The SMRs for cancer of the prostate, malignant melanoma of the skin, and leukaemia were raised, but none was significant.

Of the 827 employees with 20 or more years since first potential exposure, 730 could be classified by level of exposure. Due to the additional years of follow up, 12 employees from the Texas plant (five from the none to light exposure group and seven from the moderate to heavy exposure group) met the 20 or more years since first potential exposure criterion and were added to the analysis. Table 2 presents the mortality experience of these employees by level of potential exposure to epichlorohydrin. The SMRs for overall causes and all cancer were higher in the moderate to heavy exposure group, but the differences were not remarkable and were not significant. For example, the SMR for all cancer was 74.6 (95\% CI 46.8-112.6) in the lower exposure group and was 93.8 (95\% CI 62.8-135.0) in the higher exposure group. For lung cancer, the SMR for the higher exposure group (SMR $68 \cdot 8)$ was about the same as that for the none to light group (SMR 63.2). There was no indication of any potential dose-response relation for cancer of the prostate or for malignant melanoma of the skin. Two of the three leukaemia cases occurred in the moderate to heavy potential exposure group with an SMR of $217 \cdot 4(95 \%$ CI $26 \cdot 3-784 \cdot 8)$ and one occurred in the none to light exposure group (SMR 128.2, 95\% CI 3·2-714.1).

Mortality from heart disease was slightly higher (SMR 75.7, 95\% CI 51.8-106.7) in the moderate to heavy potential exposure group than in the none to light exposure group (SMR 59.5, 95\% CI 37·7-89.3). The differ-

Table 2 Observed and expected deaths and SMRs for employees with $\geqslant 20$ y since first potential exposure to epichlorohydrin by estimated level of exposure, 1960-93

\begin{tabular}{|c|c|c|c|c|c|c|}
\hline \multirow[b]{4}{*}{ Cause of death (ICD-8) } & \multicolumn{6}{|c|}{ Level of potential exposure } \\
\hline & \multicolumn{3}{|c|}{ None to light } & \multicolumn{3}{|c|}{ Moderate to heavy } \\
\hline & \multicolumn{3}{|c|}{ Employees $n=378$ Person-years $=6165$} & \multicolumn{3}{|c|}{ Employees $n=352$ Person-years $=6089$} \\
\hline & Observed & Expected & $S M R(95 \% C I)$ & Observed & Expected & $S M R(95 \% C I)$ \\
\hline \multirow{13}{*}{$\begin{array}{l}\text { All causes of death (000-999): } \\
\text { All malignant neoplasms (140-209): } \\
\text { Digestive system and peritoneum } \\
(150-159) \\
\text { Lung }(162) \\
\text { Prostate }(185) \\
\text { Kidney }(189) \\
\text { Malignant melanoma of skin (172) } \\
\text { Central nervous system }(191-192) \\
\text { All lymphopoietic tissue }(200-209) \\
\text { Leukaemia and aleukaemia } \\
\text { (204-207) } \\
\text { Cerebrovascular disease }(430-438) \\
\text { All heart disease (390-398, 400, 401, } \\
\text { 404, 410-414) } \\
\text { Non-malignant respiratory disease } \\
\text { (460-519) } \\
\text { All accidents (E800-E949) }\end{array}$} & $\begin{array}{l}57 \\
22\end{array}$ & $\begin{array}{l}98 \cdot 96 \\
29 \cdot 50\end{array}$ & $\begin{array}{l}57 \cdot 6(44 \cdot 0-75 \cdot 2) \\
74 \cdot 6(46 \cdot 8-112 \cdot 6)\end{array}$ & $\begin{array}{l}78 \\
29\end{array}$ & $\begin{array}{r}108 \cdot 30 \\
30 \cdot 93\end{array}$ & $\begin{array}{l}72 \cdot 0(57 \cdot 3-90 \cdot 4) \\
93 \cdot 8(62 \cdot 8-135.0)\end{array}$ \\
\hline & & & & & & \\
\hline & 3 & $6 \cdot 37$ & $47 \cdot 1(9 \cdot 7-137$ & 5 & $6 \cdot 79$ & $-171 \cdot 6)$ \\
\hline & 8 & $12 \cdot 66$ & $63 \cdot 2(27 \cdot 2-124 \cdot 5)$ & 9 & 13.09 & $68 \cdot 8(31 \cdot 5-130 \cdot 6)$ \\
\hline & 4 & 1.44 & $277 \cdot 8(75 \cdot 6-711 \cdot 1)$ & 4 & $1 \cdot 81$ & $221 \cdot 0(60 \cdot 1-565 \cdot 7)$ \\
\hline & 0 & 0.89 & - & 1 & 0.86 & $116 \cdot 3(2 \cdot 9-647 \cdot 7)$ \\
\hline & 1 & 0.38 & $263 \cdot 2(6 \cdot 7-1465$ & 1 & 0.43 & $232 \cdot 6(5 \cdot 9-1295 \cdot 3)$ \\
\hline & 2 & 0.79 & $253.2(30.6-913.9)$ & 0 & 0.85 & \\
\hline & 3 & $2 \cdot 19$ & $137 \cdot 0(28 \cdot 2-400 \cdot 0)$ & 4 & $2 \cdot 46$ & $162 \cdot 6(44 \cdot 2-416 \cdot 3)$ \\
\hline & 1 & 0.78 & $128 \cdot 2(3 \cdot 2-714 \cdot 1)$ & 2 & 0.92 & $217 \cdot 4(26 \cdot 3-784 \cdot 8)$ \\
\hline & 1 & $4 \cdot 11$ & $24 \cdot 3(6 \cdot 2-135 \cdot 5)$ & 3 & $4 \cdot 83$ & $62 \cdot 1(12 \cdot 8-181 \cdot 4)$ \\
\hline & 23 & $38 \cdot 64$ & $59 \cdot 5(37 \cdot 7-89 \cdot 3)$ & 32 & $42 \cdot 28$ & $75 \cdot 7(51 \cdot 8-106 \cdot 7)$ \\
\hline & 2 & $\begin{array}{l}5 \cdot 49 \\
3 \cdot 35\end{array}$ & $\begin{array}{l}36 \cdot 4(4 \cdot 4-131 \cdot 5) \\
59 \cdot 7(7 \cdot 2-215 \cdot 5)\end{array}$ & $\begin{array}{l}3 \\
2\end{array}$ & $\begin{array}{l}6 \cdot 78 \\
3 \cdot 72\end{array}$ & $\begin{array}{l}44 \cdot 2(9 \cdot 1-129 \cdot 2) \\
53 \cdot 8(6 \cdot 5-194 \cdot 1)\end{array}$ \\
\hline
\end{tabular}


Table 3 Observed and expected deaths and SMRs for employees with $\geqslant 20$ y since first potential exposure to epichlorohydrin by estimated level of exposure for the first and additional follow up

\begin{tabular}{|c|c|c|c|c|c|c|}
\hline \multirow[b]{3}{*}{ Cause of death } & \multicolumn{6}{|c|}{ Level of potential exposure } \\
\hline & \multicolumn{3}{|c|}{ None to light } & \multicolumn{3}{|c|}{ Moderate to heavy } \\
\hline & Observed & Expected & $S M R$ & Observed & Expected & $S M R$ \\
\hline $\begin{array}{l}\text { All causes of death: } \\
\text { First follow up (1948-1983) } \\
\text { Additional follow up (1984-1993) } \\
\text { Total follow up (1948-1993) }\end{array}$ & $\begin{array}{l}17 \\
40 \\
57\end{array}$ & $\begin{array}{l}31 \cdot 25 \\
67 \cdot 71 \\
98 \cdot 96\end{array}$ & $\begin{array}{l}54 \cdot 4 \\
59 \cdot 1 \\
57 \cdot 6\end{array}$ & $\begin{array}{l}38 \\
40 \\
78\end{array}$ & $\begin{array}{r}39 \cdot 83 \\
68 \cdot 47 \\
108 \cdot 30\end{array}$ & $\begin{array}{l}95 \cdot 4 \\
58 \cdot 4 \\
72 \cdot 0\end{array}$ \\
\hline $\begin{array}{l}\text { All malignant neoplasms: } \\
\text { First follow up (1948-1983) } \\
\text { Additional follow up (1984-1993) } \\
\text { Total follow up (1948-1993) }\end{array}$ & $\begin{array}{r}5 \\
17 \\
22\end{array}$ & $\begin{array}{r}8 \cdot 06 \\
21 \cdot 44 \\
29 \cdot 50\end{array}$ & $\begin{array}{l}62 \cdot 0 \\
79 \cdot 3 \\
74 \cdot 6\end{array}$ & $\begin{array}{l}15 \\
14 \\
29\end{array}$ & $\begin{array}{l}10 \cdot 17 \\
20.76 \\
30.93\end{array}$ & $\begin{array}{r}147 \cdot 5 \\
67 \cdot 4 \\
93 \cdot 8\end{array}$ \\
\hline $\begin{array}{l}\text { All heart disease: } \\
\text { First follow up (1948-1983) } \\
\text { Additional follow up (1984-1993) } \\
\text { Total follow up (1948-1993) }\end{array}$ & $\begin{array}{r}5 \\
18 \\
23\end{array}$ & $\begin{array}{l}12 \cdot 75 \\
25 \cdot 89 \\
38 \cdot 64\end{array}$ & $\begin{array}{l}39 \cdot 2 \\
69 \cdot 5 \\
59 \cdot 5\end{array}$ & $\begin{array}{l}17 \\
15 \\
32\end{array}$ & $\begin{array}{l}16 \cdot 13 \\
26 \cdot 15 \\
42 \cdot 28\end{array}$ & $\begin{array}{r}105 \cdot 4 \\
57 \cdot 4 \\
75 \cdot 7\end{array}$ \\
\hline
\end{tabular}

Table 4 Observed and expected deaths and SMRs for employees with $\geqslant 20$ y since first potential exposure to epichlorohydrin by location and estimated level of exposure, 1960-93

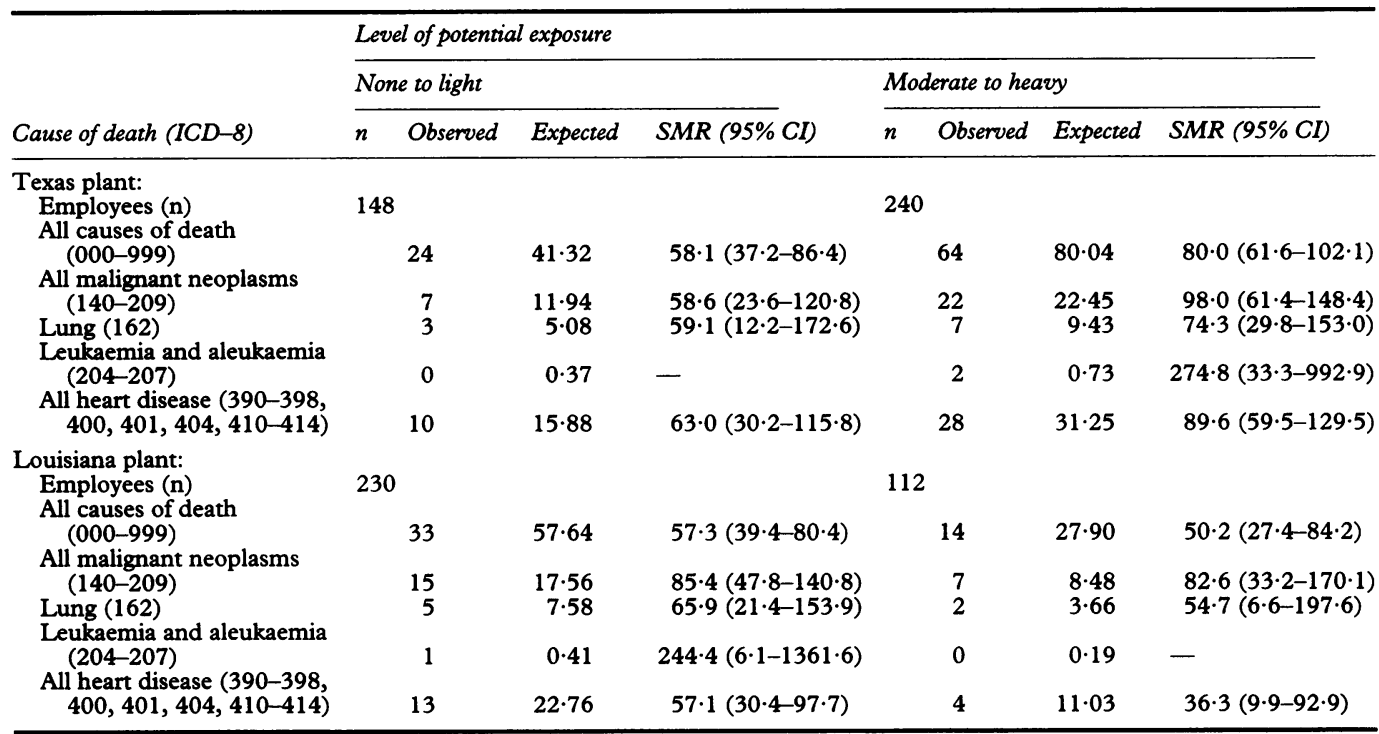

ence is within the range of statistical variation. For the additional follow up period 1984-93 the SMR for heart disease was $69.5(95 \%$ CI 41.2-109.8) for the none to light exposure group and was $57 \cdot 4$ (95\% CI 32.1-94.6) for the moderate to heavy exposure group (table 3).

Table 4 shows a further breakdown by plant location. The heart disease mortality among the Texas plant employees who had moderate to heavy potential exposure to epichlorohydrin was higher (SMR 89.6, 95\% CI 59.5-129.5) but was not significantly different from that of the none to light group (SMR 63.0, 95\% CI $30 \cdot 2-115 \cdot 8)$. The reverse was true for the Louisiana plant $(36.3 v 57 \cdot 1)$.

Employees who had potential exposure to both epichlorohydrin and allyl chloride were also examined. There were 160 people who had moderate to heavy potential exposure to epichlorohydrin and probable exposure to allyl chloride at the Texas plant; the SMR for heart disease for this group of employees was 90.4 (95\% CI 53.6-1142.9). The SMR for heart disease was $88.2(95 \%$ CI $42 \cdot 3-162 \cdot 3)$ for the remaining 88 employees who had moderate to heavy exposure to epichlorohydrin but no exposure to allyl chloride. All workers at the Louisiana plant were potentially exposed to both epichlorohydrin and allyl chloride; the SMR for heart disease was only 36.3 among employees in the moderate to heavy exposure to epichlorohydrin group (table 4).

\section{Discussion}

Ten additional years of follow up for employees with potential exposure to epichlorohydrin at two chemical plants was conducted. Personyears for workers with 20 or more years after first exposure increased by $112 \%$ compared with the original study. ${ }^{1}$ The additional 10 years of follow up has increased the proportion of decedents and the precision of the study to determine more accurately whether the earlier findings showed a potentially increased risk of heart disease from occupational exposure to epichlorohydrin. As with the previous study, this update showed that the overall mortality was significantly lower than the comparable mortality among residents of the surrounding communities. The favourable overall mortality experience in a working population has been referred to as the healthy worker effect, and has been attributed to several factors. ${ }^{13-16}$ The selection of relatively healthy people into the workforce plays an important part. The positive socioeconomic effects of continuing 
employment with its many benefits including greater access to medical care may also contribute.

The mortality for all malignant neoplasms was also lower (SMR 83) and was not much different from that reported by Enterline el al. ${ }^{1}$ There was no significant excess mortality for any cause of death, although several cancer sites showed a raised $S M R,{ }^{5}$ including cancer of the prostate and malignant melanoma of the skin. There was no apparent dose-response relation for these two malignancies, and thus a possible cause related to exposure is unlikely. There were no additional deaths due to leukaemia in this update; the mortality due to leukaemia in the current study for employees with 20 or more years since first potential exposure was substantially lower than the one published earlier (SMR 500) ${ }^{1}$ although it was moderately raised with an SMR of 161 .

Lung cancer mortality was substantially lower than that of the comparison populations, and there was no relation with exposure. A recent study of workers with potential exposure to epichlorohydrin and allyl chloride conducted by Olsen et al also supports this finding. ${ }^{4}$ In 1989 , a retrospective follow up study which evaluated the mortality experience of 2642 white men employed at a dye and resin manufacturing plant found an increased lung cancer mortality in a subgroup of 44 workers who were involved in epichlorohydrin production (four observed $v \quad 0.9$ expected deaths). ${ }^{5}$ In a subsequent nested case-control study of lung cancer, based on all lung cancer deaths in the cohort study, there was a $70 \%$ increased risk of lung cancer among all workers with potential exposure to epichlorohydrin. ${ }^{6}$ The excess of lung cancer was restricted to people with a short duration of potential exposure and low cumulative potential exposure; risks were lower for people with longer duration (10 years or longer) or higher cumulative exposure (50 units or greater). The authors concluded that "Our study does not provide clear evidence of a causal relationship between lung cancer and epichlorohydrin". ${ }^{6}$

The mortality from heart disease among employees with 20 or more years after first potential exposure to epichlorohydrin in this update was about the same as that found in the original study, which was $30 \%$ lower than in the local populations. In the earlier study, the death rate for heart disease in the moderate to heavy potential exposure group was essentially the same as that for the comparison population (SMR 105), but it was more than twofold higher when compared with the none to light exposure group (SMR 39). Interestingly, for deaths due to heart disease, the mean age at death for the moderate to heavy potential exposure group was about five years older than that of the none to low exposure group, which is the opposite of what would be expected for an outcome induced by exposure. ${ }^{7}$

With 10 years of additional follow up, the twofold increased mortality for heart disease no longer exists, and the SMR for the heavier exposure group is about the same as that of the lighter exposure group (76 v 60). In the current study, the difference in mortality from heart disease between exposure groups for the Texas plant is substantially less than the difference reported by Enterline et al. For the Louisiana plant, the difference between exposure groups is in the opposite direction to the difference reported in the original study; the current study showed higher mortality in the lower exposure group. Also, for the additional follow up period 1984-93, the mortality (SMR) for heart disease was lower for the heavier exposure group than the lighter exposure group (57 $v 70$ ). Although the original data published by Enterline et al showed a difference between exposure groups that approached significance for heart disease $(P<0.07)$, the results were not stable. The numbers of deaths from heart disease in that study were too small (five in the none to light exposure group and 17 in the moderate to heavy exposure group) to provide a stable risk estimate. In the current update, the number of deaths from heart disease has more than doubled (23 in the none to light group and 32 in the moderate to heavy group), thus providing more stable results.

Based on the Texas chemical plant data, Enterline $e t$ al raised the question of a potential association between heart disease and those who had exposure to both allyl chloride and epichlorohydrin. ${ }^{1}$ According to Enterline et al, the SMR for cardiovascular disease was 121 among Texas employees where allyl chloride and moderate to heavy potential exposure to epichlorohydrin may have occurred; for employees who had moderate to heavy exposure to epichlorohydrin but no allyl chloride exposure the SMR for cardiovascular disease was 65 (based on five deaths). The SMRs for heart disease in the current study for the corresponding groups were 90.4 and 88.2 , respectively.

Enterline et al further suggested that "If heart disease is truly increased by exposure to epichlorohydrin there may not be a long latent period, as is likely for cancer." 1 To consider these issues, Tsai et al examined the morbidity experience between 1981 and 1988 of employees who worked at the same plants and were potentially exposed to epichlorohydrin. ${ }^{8}$ There was no effect related to exposure to epichlorohydrin on heart disease morbidity. For those who had probable potential exposure to allyl chloride and higher potential exposure to epichlorohydrin, the standardised morbidity ratio (SMbR) was similar to that for employees who were not exposed to allyl chloride (SMbR $92 v$ SMbR 109 for those not exposed). If a true association had existed between exposure to epichlorohydrin and heart disease, the pattern of morbidity for heart disease should have been similar to that of mortality for heart disease found in the study of Enterline et al.

Based on a small preliminary study of employees with potential for exposure to epichlorohydrin (12 total deaths) conducted by Dow Chemical Company (Shellenberger et 
al, 1979, unpublished report), Enterline et al suggested that people with potential exposure to epichlorohydrin and allyl chloride were at an increased risk of dying from cardiovascular disease. ${ }^{1}$ Recently, Olsen et al conducted a retrospective cohort mortality study of workers with potential exposure to epichlorohydrin and allyl chloride. That study, which was stratified by levels of exposure to allyl chloride and exposure to epichlorohydrin, showed that the cardiovascular mortality risk did not increase with higher cumulative exposures to allyl chloride. ${ }^{4}$ For example, the SMRs for circulatory disease for no and high allyl chloride exposure among employees with high exposure to epichlorohydrin were 108 (95\% CI 40-235) and 117 (95\% CI 64-196), respectively. For employees in the low epichlorohydrin group, the SMRs for no, low, and high allyl chloride exposure were 89 (95\% CI 23-215), 128 (95\% CI 58-242), and 63 (95\% CI 13-185), respectively.

In summary, the overall mortality and cancer mortality of employees potentially exposed to epichlorohydrin continued to be lower than for the residents in the surrounding communities. This study did not examine other possible concomitant exposures or lifestyle factors (smoking, diet, etc) which may have had an influence on mortality. Another limitation is the lack of quantitative data on exposure to epichlorohydrin to assign the exposure category. There were no new deaths due to leukaemia; the raised SMR noted in the original study has decreased substantially in this update. Mortality from lung cancer was lower than the general population, which does not support an association with exposure to epichlorohydrin. The twofold increased mortality from heart disease among employees who had higher potential exposure to epichlorohydrin, as reported in the earlier study, is not substantiated by the present study. Finally, the mortality from heart disease for employees who had high exposure to epichlorohydrin and allyl chloride was not different from those who had high exposure to epichlorohydrin but no exposure to allyl chloride.

1 Enterline PE, Henderson V, Marsh G. Mortality of workers potentially exposed to epichlorohydrin. $\mathrm{Br} F$ Ind Med 1990;47:269-76.

2 Tassignon JP, Bos GD, Craigen AA, et al. Mortality in a European cohort occupationally exposed to epichlorohydrin (ECH). Arch Occup Environ Health 1983;51:325-36.

3 Enterline PE . Arch Occup Environ Health $1983,51.325-36$. production of epichlorohydrin and isopropanol. In: Brain tumours in the chemical industry. New York Academy of tumours in the chemical

4 Olsen GW, Lacy SE, Chamberlin SR, et al. A retrospective mortality study of workers with potential exposure to mortality study of workers with potential exposure to
epichlorohydrin and allyl chloride. Am F Ind Med 1994; 25:205-18.

5 Delzell E, Macaluso M, Cole P. A follow-up study of workers at a dye and resin manufacturing plant. $\mathcal{F}$ Occup Med 1989;31:273-8.

6 Barbone F, Delzell D, Austin H, Cole P. A case-control study of lung cancer at a dye and resin manufacturing plant. Am F Ind Med 1992;22:835-49.

7 Ross CE. Mortality among workers exposed to epichlorohydrin. $\mathrm{Br}$ F Ind Med 1990;47:789.

8 Tsai SP, Cowles SR, Tackett DL, Barclay MT, Ross CE. Morbidity prevalence study of workers with potential exposure to epichlorohydrin. Br $\mathcal{f}$ Ind Med 1990;47: exposu

9 Tsai SP, Wen CP. A review of methodological issues of the standardised mortality ratio (SMR) in occupational cohort studies. Int $\mathcal{F}$ Epidemiol 1986;15:8-21.

10 Marsh GM, Preininger ME. A user-oriented occupational cohort mortality analysis program. American Statistician 1980;34:245.

11 Marsh GM, Ehland J, Sefcik S. Mortality and population data system (MPDS). Pittsburg: University of Pittsburgh, Department of Biostatistics, 1980. (Technical Report.)

12 Bailar JC, Ederer $F$. Significance factors for the ratio of a Poisson variable to its expectation. Biometrics 1964;20: 639-42.

13 Fox AJ, Collier PF. Low mortality rates in industrial cohort studies due to selection for work and survival in the studies due to selection for work and sur
industry, Br 7 Prev Soc Med 1976;30:225-30.

14 Ott MG, Holder BB, Langner RR. Determinants of mortality in an industrial population. $\mathcal{F}$ Occup Med 1976;18: 171-7.

15 Wen CP, Tsai SP, Gibson RL. Anatomy of the healthy worker effect: a critical review. $\mathcal{F}$ Occup Med 1983;25: 283-9.

16 Monson RR. Observations on the healthy worker effect. $\mathcal{f}$ Occup Med 1986;28:425-33.

\section{Occupational and Environmental Medicine and the electronic age}

OEM has an Email address which is 100632.3615@compuserve.com. We welcome contact by Email, including letters to the editor. Some of our reviewers already send us their reports by Email, helping to speed up the peer review process.

We are moving towards electronic publishing and for some months now we have been asking authors to send us their revised papers on disk as well as a hard copy. I am delighted to report that nearly all our authors are managing to comply with this request; far more than for other specialist journals in the BMJ Publishing group. Oddly enough, the few authors who have not sent us a disk version of their revised papers have been almost exclusively from the United Kingdom. I would be interested in suggestions for why this might be. Perhaps United Kingdom based authors read our correspondence and instructions less assiduously? Watch for revised Instructions to Authors.

The Editor 